\title{
SPIRITUAL HEALTH AND COPING SKILLS AMONG FIRST YEAR MEDICAL STUDENTS
}

\author{
Asha Joan Murali1, Rosin George Varghese2, Geetha Devi Madhavikutty³, Sobha A4 \\ 1 Junior Resident, Department of Community Medicine, Government Medical College, Kottayam. \\ 2Junior Resident, Department of Community Medicine, Government Medical College, Kottayam. \\ ${ }_{3}^{3}$ Associate Professor, Department of Community Medicine, Government Medical College, Kottayam. \\ 4 Professor and HOD, Department of Community Medicine, Government Medical College, Kottayam.
}

\section{ABSTRACT}

\section{BACKGROUND}

Spiritual Health is one of four dimensions to well-being as defined by the World Health Organisation (WHO), which include physical, social and mental; it is a highly unaddressed and valuable component yet to be explored. Medical school is recognised as a stressful environment that often exerts a negative effect on the academic performance, physical health and psychological well-being of the student. This study aims to measure the spiritual health status and describe the coping skills of young medical graduates who are the caregivers of the future and to determine the association of spiritual health status of the study population and their coping skills.

\section{MATERIALS AND METHODS}

An institution-based cross-sectional study was performed among 138 first semester medical students in Government Medical College, Kottayam, from November 2015 to December 2015 by the survey questionnaire method. The Spiritual Health Assessment Scale and the Brief COPE Scale were used to measure the spiritual health and coping status, respectively.

\section{RESULTS}

Of all the participants, only $31.2 \%$ had Good spiritual health. The mean spiritual health score of the female students was higher than that of the males. Of all the respondents, $97.8 \%$ and $37.7 \%$ had higher adaptive and maladaptive coping scores, respectively. Female medical students showed significantly higher adaptive coping and religious coping, whereas male students scored higher in humorous coping. Self-actualisation domain of spiritual health was significantly related to the adaptive coping scores and other coping strategies like turning to religion and humor.

\section{CONCLUSION}

Among the medical students, only 31.2\% had Good spiritual health. Further exploration and development of spiritual health and adequate assessment and balancing of coping strategies among undergraduates is recommended.

\section{KEYWORDS}

Spiritual Health, Coping Skills, Fourth Dimension of Health.

HOW TO CITE THIS ARTICLE: Murali AJ, Varghese RG, Madhavikutty GD, et al. Spiritual health and coping skills among first year medical students. J. Evolution Med. Dent. Sci. 2016;5(82):6088-6092, DOI: 10.14260/jemds/2016/1376

\section{BACKGROUND}

Health as defined by WHO in 1946 "is a state of complete physical, mental and social well-being and not merely the absence of the disease or infirmity." However, it seems that there was a general feeling from the very beginning that a fourth dimension was missing from this definition, a vacuum that led to widespread psychological insecurity with the consequent deleterious effects on mental and physical health. And hence in May 1984, the Thirty-Seventh World Health Assembly took the historic decision to adopt this element, which made the "spiritual dimension" part and parcel of WHO Member States' strategies for health. ${ }^{1}$

Spiritual health has been defined as "a state of being where an individual is able to deal with day-to-day life in a manner,

Financial or Other, Competing Interest: None.

Submission 24-08-2016, Peer Review 29-09-2016,

Acceptance 05-10-2016, Published 11-10-2016.

Corresponding Author:

Dr. Asha Joan Murali,

Junior Resident,

Department of Community Medicine,

Government Medical College, Kottayam

E-mail: ashajoan1611@gmail.com

DOI: $10.14260 /$ jemds/2016/1376

\section{(c) $(1)$}

which leads to the realisation of one's full potential; meaning and purpose of life; and happiness from within."2

It is a highly unaddressed and valuable component yet to be explored and its significance can be further emphasised in the words of Stuckelberger3: "Addressing the scientific link between religion, spirituality and health has too often been a 'forgotten subject' or avoided for irrational, emotional or 'political' reasons. It is time for the scientific community to integrate religious and spiritual factors, which have guided human behaviour over centuries into health and human sciences."

Spiritual health status of the population at large is still unknown in India. Whether spiritual health has any relation with the coping skills of an individual is yet to be explored. Procuring this knowledge may help individuals to overcome crisis situations better. Medical school is recognised as a stressful environment that often exerts a negative effect on the academic performance, physical health and psychological well-being of the student.

Moreover, a spiritual caregiver can provide better patient care and it is important for caregivers to have a spiritual orientation, hence these aspects can be explored among young medical undergraduates and the lessons learnt from this study may help to improve the quality of care provided by these 
young caregivers in the future. This study aims to measure spiritual health status of study population and describe coping skills used by them in a crisis situation. Also to identify sociodemographic factors associated with their spiritual health and coping skills and to determine the association of spiritual health status of the study population and their coping skills.

\section{METHODOLOGY}

A Cross-sectional Analytical study was conducted in Government Medical College, Kottayam, from November 2015 to December 2015 among First semester MBBS Undergraduates.

In a study conducted by Shibotosh Sen et al, "Spiritual Health of Students in Government Medical Colleges of Kolkata and their Coping Skills in a Crisis Situation,"4 the proportion of refined spiritual health was $75.7 \%$.

Based on this data, the minimum sample size required for the study was calculated using the formula.

\begin{tabular}{c}
$\mathrm{N}=\frac{\mathrm{Z}_{\alpha} \underline{\underline{2}}}{\mathrm{~d}^{2}}-\underline{\mathrm{PQ}}$ \\
$\mathrm{N}=\frac{1.96 \times 1.96 \times 75.7 \times 24.3}{8 \times 8}=110$ \\
\hline
\end{tabular}

Taking into account non-response and dropouts 138 undergraduate medical students were selected by convenient sampling. After obtaining institutional clearance and verbal consent, the students were administered a semi structured questionnaire prepared as per the Spiritual Health Assessment Scale developed by Dr. Kusum Lata Gaur and Dr. Mahesh Sharma published in Indian Journal of Innovative Research and Development ${ }^{5}$ and the Brief COPE Scale of the University of Miami, Coral Gables, FL, USA.6,7 The initial questions procured details regarding their sociodemographic and religious background, academic performance and support from family, etc.

The SHA Scale ${ }^{5}$ contains three domains for the assessment of Spiritual health; Self-development, Self-Actualisation and Self-Realisation. Each of the domains have seven items in itself related to each domain.

The trait version of the Brief COPE6,7 asks respondents about the coping strategies they use during periods of stress. Twenty eight items assess 14 conceptually different forms of coping. It included adaptive coping (Active coping, seeking instrumental support, seeking emotional support, planning and positive reframing), maladaptive coping or withdrawing from the problem (Denial, behavioural disengagement, alcohol and drug use, self-distraction and self-blame) and other common strategies that do not clearly fall into either of the three categories (Acceptance, turning to religion, humor and focus on venting emotions).

Each of the 21 items on SHA scale was given scoring of between ' 1 ' to ' 5 ' on Likert scale. Likewise, total spiritual health score ranges from ' 21 ' to '105.' "Poor spiritual health" was considered when spiritual health score between ' 21 ' to '49,' "fair spiritual health" was considered when spiritual health score between ' 50 ' to '77' and "good spiritual health" was considered when spiritual health score between '78' to '105.'

In the Brief COPE Scale, there were 28 assertions (each with a minimum 1 mark and maximum 4 marks) contributing to 14 attributes; 5 attributes account for Adaptive coping, 5 attributes for maladaptive coping and the remaining for 4 attributes for other common strategies: Acceptance, Turning to Humor, Religion and Venting. Since no specific guideline was stated in the Brief COPE Scale, it was decided to fix a cutoff value of $50 \%$ of the scores obtained in the survey. The subjects having scores more than the cutoff were considered to use the specific coping skill attributes or strategies more.

Data was coded and entered in Microsoft Excel and analysed using IBM SPSS version 16. Association between spiritual health and coping skills and other socio-demographic factors was assessed using Chi square test for qualitative variables. The level of statistical significance will be $p$ value less than 0.05 .

\section{RESULTS}

Among the medical students aged between 17 years and 29 years (Mean 18.8 years) $60.9 \%$ of the respondents were females. Of all the students $54.3 \%$ were Hindus, $14.5 \%$ Muslims and $31.2 \%$ belonged to Christianity. Among them $86.2 \%$ hailed from nuclear families; $61.6 \%$ belonged to upper class and $38.4 \%$ to middle class families according to the Modified Kuppuswamy Scale 2014.

Of all the students $52.2 \%$ felt that their overall academic performance was good; $92.8 \%$ of the study population thought that the relations between their parents were excellent, which indirectly states that the internal conflicts between those families were less. Of all the students, only $2.2 \%$ felt that they were not getting physical and mental support from their families at the time when they need it the most. Of all the students' families, $98.6 \%$ arranged social gatherings at their home.

\begin{tabular}{|c|c|c|c|c|c|c|c|}
\hline \multirow{2}{*}{$\begin{array}{c}\text { Spiritual } \\
\text { Health } \\
\text { Variable }\end{array}$} & \multicolumn{3}{|c|}{ Good Status in \% } & \multirow[b]{2}{*}{ P value } & \multicolumn{3}{|c|}{ Ranges Found in the Survey } \\
\hline & $\begin{array}{l}\text { Total } \\
(138)\end{array}$ & $\begin{array}{l}\text { Males } \\
(54)\end{array}$ & $\begin{array}{c}\text { Females } \\
\text { (84) }\end{array}$ & & $\begin{array}{c}\text { Minimum } \\
\text { Score }\end{array}$ & $\begin{array}{c}\text { Maximum } \\
\text { Score }\end{array}$ & $\begin{array}{l}\text { Mean } \\
\text { Score }\end{array}$ \\
\hline Spiritual Health & $\begin{array}{c}43 \\
(31.2 \%) \\
\end{array}$ & $\begin{array}{c}15 \\
(27.8 \%)\end{array}$ & $\begin{array}{c}28 \\
(33.3 \%) \\
\end{array}$ & 0.492 & 53 & 91 & 73.9565 \\
\hline Self-Development & $\begin{array}{c}138 \\
(100 \%)\end{array}$ & $\begin{array}{c}54 \\
(100 \%)\end{array}$ & $\begin{array}{c}84 \\
(100 \%)\end{array}$ & - & 11 & 33 & 25.3986 \\
\hline Self-Actualisation & $\begin{array}{c}133 \\
(96.4 \%)\end{array}$ & $\begin{array}{c}49 \\
(90.7 \%)\end{array}$ & $\begin{array}{c}84 \\
(100 \%)\end{array}$ & 0.004 & 12 & 28 & 22.6377 \\
\hline Self-Realisation & $\begin{array}{c}125 \\
(90.6 \%)\end{array}$ & $\begin{array}{c}45 \\
(83.3 \%)\end{array}$ & $\begin{array}{c}80 \\
(95.2 \%)\end{array}$ & 0.019 & 18 & 31 & 25.9203 \\
\hline
\end{tabular}


Among 133 students who had good Self-Actualisation, $63.2 \%$ were females and only $36.8 \%$ were males which was statistically significant with a Chi square value 8.070 and $p$ value 0.004 . Female students also showed significantly higher Self-realisation domain with Chi square value 5.459 and $\mathrm{p}$ value 0.019 .

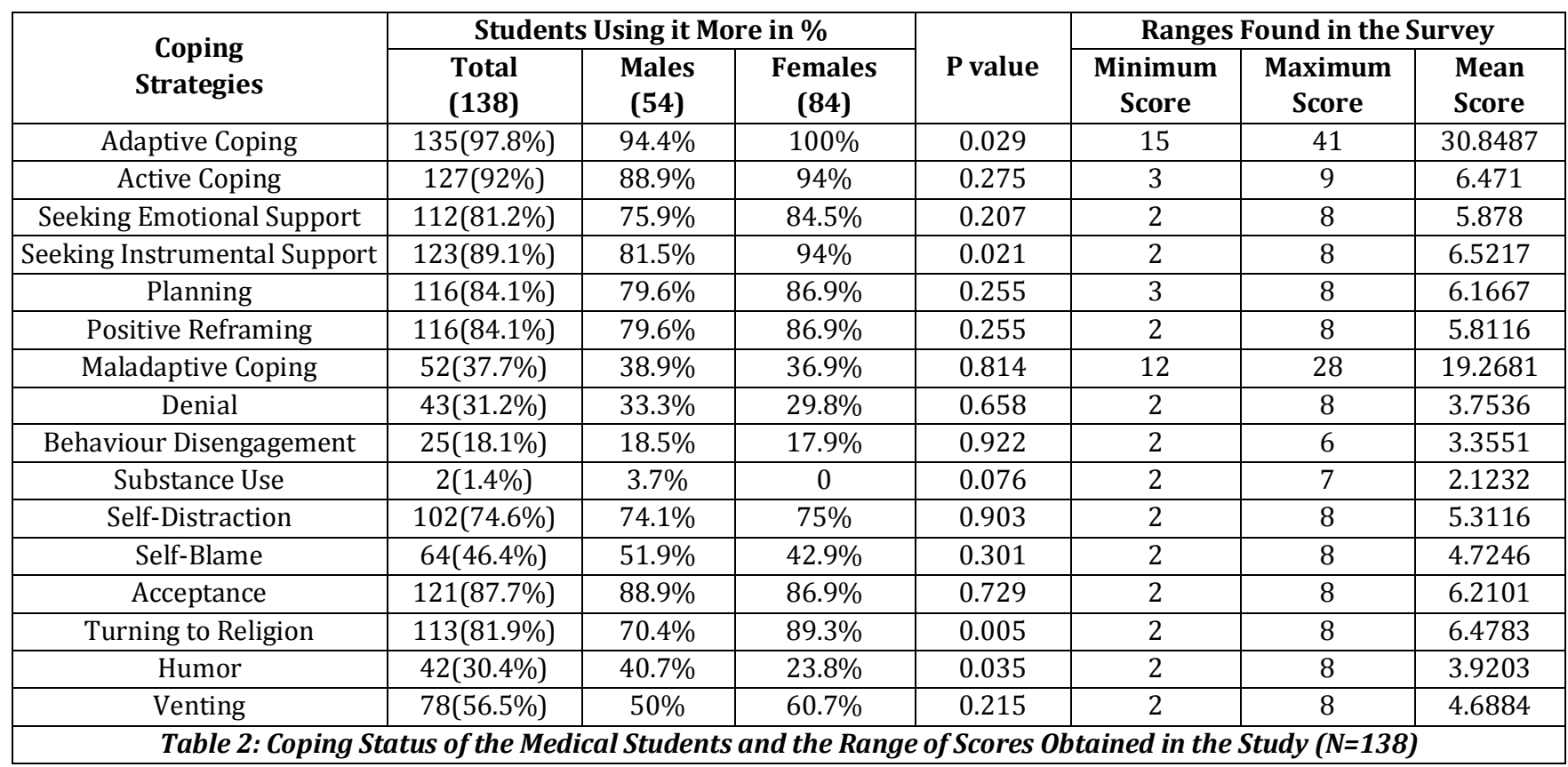

In the results of coping skills also the gender criterion showed that females had significantly higher Adaptive coping skills at the time of a crisis situation with a Chi-square value 4.770 and $p$ value of 0.029 . Female students adopted Adaptive coping strategies like Seeking Instrumental support more than male students to deal with a crisis (Chi square $=5.537, \mathrm{p}$ value $=0.021$ ). Interestingly female students had significantly higher Religious coping (Chi square $=7.928$ and $p$ value $=0.005$ ) and male students had higher Humorous coping (Chisquare $=4.450$ and $\mathrm{p}$ value $=0.035$ ).

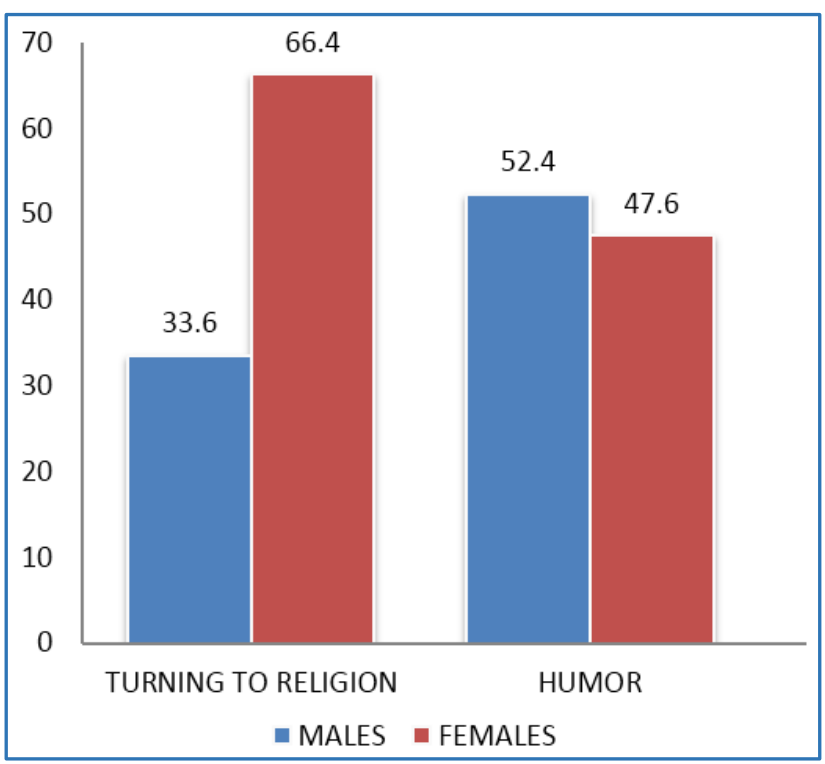

Fig. 1: Coping Strategies: Association with Gender

Turning to Religion-Chi Square $=7.928$, $\mathrm{p}$ value $=0.005$. Humour - Chi Square $=4.450$, $\mathrm{p}$ value $=0.035$.

As for association between Spiritual health and coping skills, it was found that certain attributes of coping skills significantly differ with the individual domains of spiritual health like Self Actualisation and Self Realisation. Selfactualised individuals had significantly higher coping attributes like adaptive coping (Chi square=34.905, p value $=0.0001$ ), turning to religion (Chi square $=6.135, p$ value $=0.013$ ). Students with higher Self-realisation scores had significantly better coping skills like Seeking instrumental support at the time of a crisis (Chi-Square $=5.886, \mathrm{p}$ value $=0.015$ ) and significantly lower Maladaptive coping skills like Behaviour Disengagement (Chi-square $=4.005, \mathrm{p}$ value $=0.045$ ).

There was also significant association between Good spiritual health and coping strategies like Planning and turning to religion. Self-actualised individuals used Humorous coping more than others ( $p$ value $=0.031$ ). Students with higher Self-actualisation scores also felt that their overall academic performance was good $(p=0.0001)$.

\section{DISCUSSION}

Females scored significantly higher in domains of spiritual health like 'Self-actualisation' and 'Self-realisation;' they also fared significantly better at Adaptive coping skills like 'Seeking Instrumental support.' Shibotosh Sen et $\mathrm{al}^{4}$ conducted a study among undergraduates in Government Medical Colleges of Kolkata also found that female students were having better spiritual health when compared to their male counterparts.

High scores of Self-actualisation was significantly associated with Adaptive coping, religious and humorous coping strategies. Self-actualised students were also more satisfied and confident about their academic performance. Maslow noticed that self-actualised individuals had a better insight of reality; deeply accepted oneself, others and the world; had also faced many problems; and were known to be impulsive people. These self-actualised individuals were very independent and private when it came to their environment and culture, especially their very own individual development 
on "potentialities and inner resources."8 In this study also, it was found that the self-actualised students had higher scores of adaptive coping strategies and they were trying to develop their potential inner resources. But there will be error if we mix up both the Self-Actualisation categories. Maslow refers to such category as a certain mental state that is achieved at a certain stage of life according to the hierarchy of need. ${ }^{9}$ But here the said attribute appears as a spectrum that is present throughout life, though the characteristics of the selfactualised person suggested by Maslow remains the same.

The apparent contradiction between coping strategies; significantly higher scores for female students in turning to religion at the time of a crisis and male students using humour as coping strategy significantly more than their female counterparts may be explained with respect to the sociocultural aspect of our country.

Bansal et al $^{10}$ showed that spiritual practices have a positive correlation with survival, low blood pressure, less remission time from depression, less number of cigarettes smoked, less severe medical illness, better quality of life, cooperativeness, etc. They suggest a positive relation between spiritual practices and positive health outcomes like greater self-confidence, assertiveness and fewer symptoms of anxiety and depression. Evidence shows that spiritual well-being is positively related with self-ratings of physical health and vitality. In this study, students with higher Self-actualisation scores felt were more confident with their overall academic performance.

Brougham et al ${ }^{11}$ found that college students of both genders who employ problem-solving strategies have better health and increased self-esteem. In our study, higher selfrealisation helped individuals to have adaptive coping strategies like seeking instrumental help and to reduce maladaptive scores like behaviour disengagement.

Thus, as Shibotosh Sen et al ${ }^{4}$ highlighted, the so-called triad of health may be improved by a new concept of health balance. Here, it is emphasised that balance between the coping skills influences health in which the spiritual component plays a central role. Further, this spiritual component continuously equilibrates with other components like physical, mental and social well-being. The balance is continuously maintained between adaptive coping and maladaptive coping. The additional weightage of "other coping attributes" can be distributed to either side, partially or entirely according to the psychological backup of the individual.

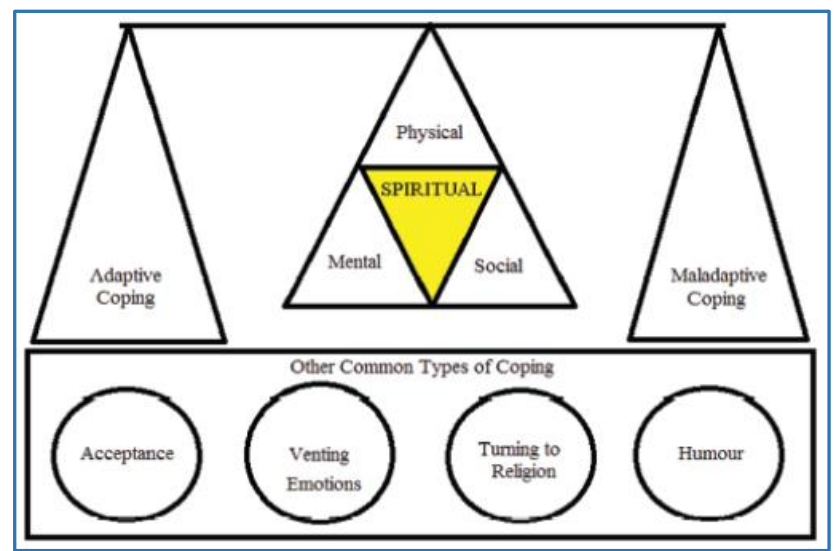

\section{CONCLUSION}

Of all the participants, only $31.2 \%$ had Good spiritual health. Among the respondents, $97.8 \%$ and $37.7 \%$ had higher adaptive and maladaptive coping scores, respectively. The coping skills and hence the spiritual health of the medical students were greatly influenced by their gender. As previous studies have shown a spiritual caregiver can provide better patient care and it is important for caregivers to have a spiritual orientation. This aspect has been explored among young medical undergraduates and the lessons learnt from this study may help to improve the quality of care provided by caregivers in the future.

\section{RECOMMENDATIONS}

Healthy spiritual practices like meditation helps to relax the mind and improve concentration in work. At the same time, annual rituals or social gatherings help to exchange ideas and broaden the mind. Moreover, a spiritually healthy person justifies his/her ideas and works well when he/she compares his/her ideas with others. This activity may further gain social support and relax the mind.

It is not that spiritual awakening emerges in a later stage of life, rather spiritual health is everlasting throughout life and somehow influences us to cope with adversities. Along with the life skill education program, development of spiritual health and augmentation of adaptive coping skills in adolescents may act as a primordial prevention for depression and general anxiety disorder. Further research may necessitate its inclusion in the National Mental Health Program.

\section{LIMITATIONS}

Convenient sampling was used for the study.

\section{STRENGTHS}

Adequate sample size was achieved.

\section{REFERENCES}

1. Yach D. Report from the World Health Organization. Closing the gap in a generation: health equity through action on the social determinants of health. Available from:

http://www.en.wikipedia.org/wiki/Social_determinants _of_health.[Last accessed on 2011Sep 3].

2. Dhar N, Chaturvedi SK, Nandan D. Spiritual health scale 2011: Defining and measuring 4 dimension of health. Indian J Community Med 2011;36(4):275-82.

3. Richardson P. Spirituality: the new frontier, psychological testing at work. Chapter 12, In: Hoffman E. (edr.) New York: McGraw Hill 2002:138.

4. Sen S, Pal D, Hazra S, et al. Spiritual health of students in government medical colleges of Kolkata and their coping skills in a crisis situation. Indian Journal of Public Health 2015;59(3):196-203.

5. Gaur LK, Sharma M. Measuring spiritual health: spiritual health assessment scale. Indian Journal of Innovative Research and Development 2014;3(3):63-7.

6. Carver CS. You want to measure coping but your protocol's too long: consider the brief COPE. Int J Behav Med 1997;4(1):92-100.

Fig. 2: Concept of Health Balance 
7. Carver CS, Scheier MF, Weintraub JK. Assessing coping strategies: a theoretically based approach. J Pers Soc Psychol 1989;56(2):267-83.

8. Schott RL. Abraham maslow humanistic psychology, and organization leadership: a jungian perspective. J Humanist Psychol 1992;32(1):106-20.

9. Maslow's Hierarchy of Needs. Bob Poston, CST; The surgical technologist- August 2009:352. Available from: http://webspace.ship.edu/cgboer/maslow.html. [Last accessed on 2011 Dec 29].
10. Bansal R, Maroof KA, Parashar P, et al. Spirituality and health: a knowledge, attitude and practice study among doctors of North India. Spiritual Health Int 2008;9(4):263-9.

11. Brougham RR, Zail CM, Mendoza CM, et al. Stress, sex differences, and coping strategies among college students. Curr Psychol 2009;28(2):85-97. 